\title{
Exploring the Creation of \\ Organisation Strategy when \\ Commercialising a New Technology
}

MASTER OF ADVANCE TECHNOLOGY ENTERPRISE THESIS

\author{
BY \\ MICHAEL METTRICK \\ Submitted to the Victoria University of Wellington. \\ In partial fulfilment of the requirements for the degree of \\ Master of Advanced Technology Enterprise.
}

Victoria University of Wellington 


\section{Abstract}

This thesis takes a mixed methodology approach to exploring the creation of organisational strategy from the perspectives of both the classical strategy frameworks and Sarasvathy's theory of effectuation. The experience of working within the Masters of Advanced Technology Enterprise (MATE) is portrayed through using an ethnographic approach in conjunction with critical reflection to build 'thick descriptions'. Following this descriptive phase, analysis is conducted through both classical strategic management frameworks and Sarasvathy's theory of effectuation. The multifaceted approach was chosen enable a deep understanding of the variety of strategic directions, reasoning's that were undertaken throughout the year. 


\section{Acknowledgements}

I would like to personally thank every person whom has supported and encouraged me through what has been an interesting and eventful year.

Firstly, thank you to the course coordinators, Dr Paul Smith, David Bibby and Jenny Douche who have made this program possible.

Thank you to the project and MATE program champion Professor Kate McGrath for providing a diverse group of students with some of your research for the year.

A heartfelt thank you to my supervisor Professor James (Jim) Richards for supporting me through some of the interesting parts of the past year.

My greatest thanks and gratitude to my family and friends. Especially those whom have helped proof reader and edit my writing. In particular, Jodie Parsons, Agate Kilpatrick, Sarah Beale, and Phillip and Carolyn Mettrick. 


\section{Table of Contents}

Abstract Error! Bookmark not defined.

Acknowledgements iv

Chapter 1 - Introduction and course overview 1

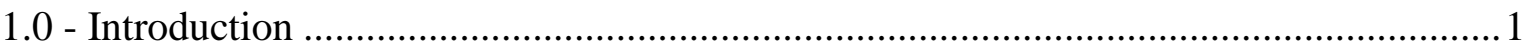

1.1 - Masters of Advanced Technology Enterprise ........................................................... 1

1.2 Project Origin and Project Champion ..................................................................... 1

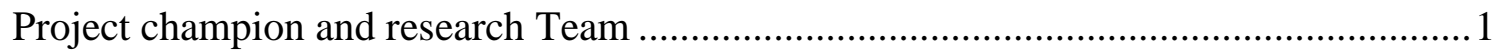

Base research and origins of NacreTech project....................................................... 1

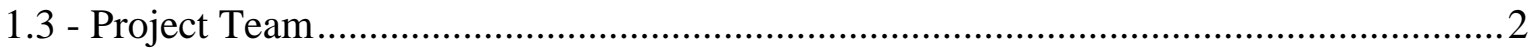

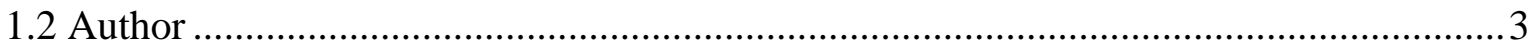

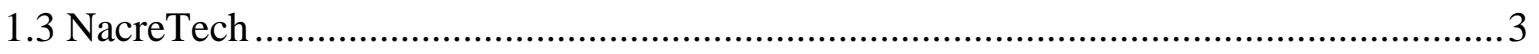

1.4 Role within the NacreTech team..........................................................................

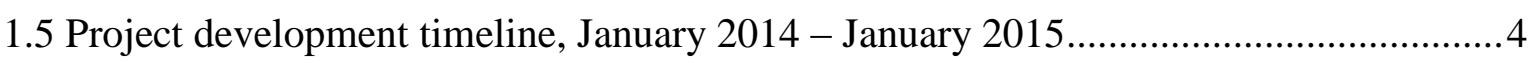

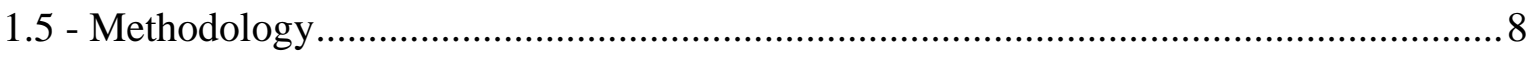

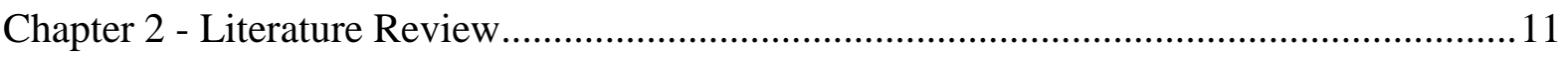

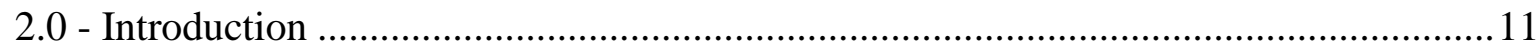

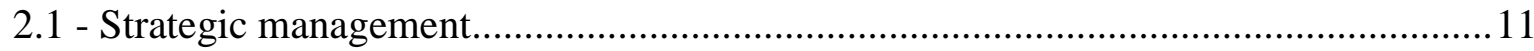

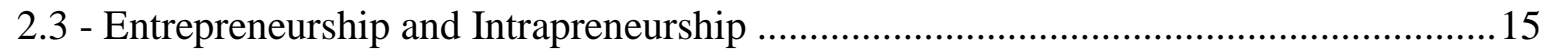

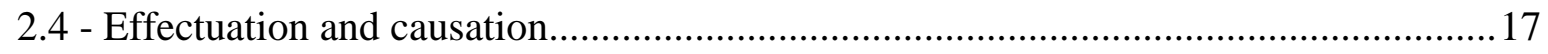

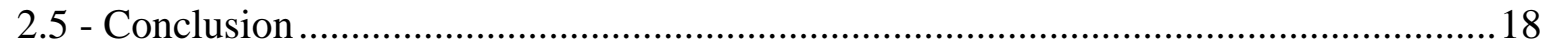

Chapter 3 Description and critical reflection of project development timeline ...................... 19

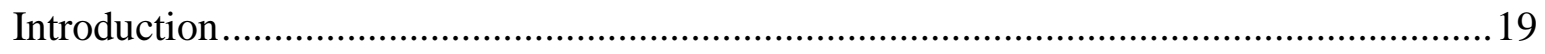

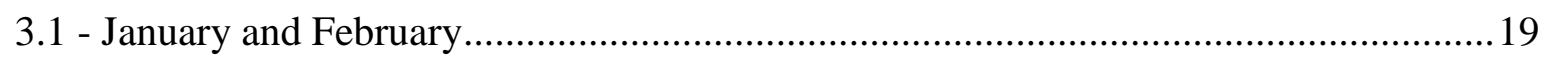

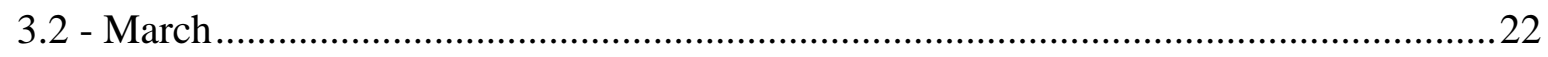

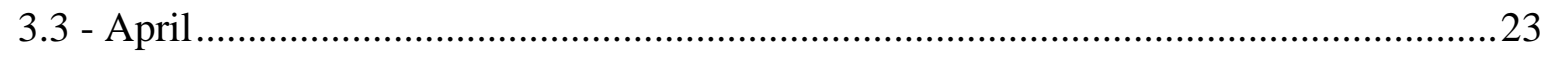

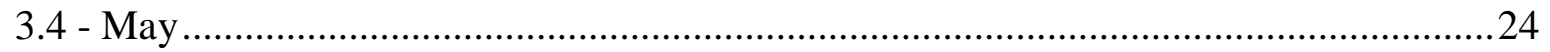




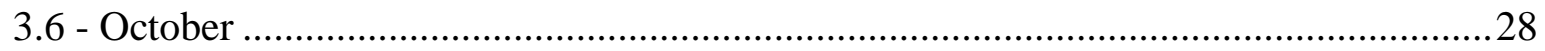

Chapter 4 Analysis of significant decision points along the timeline ......................................32

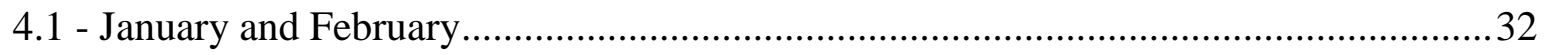

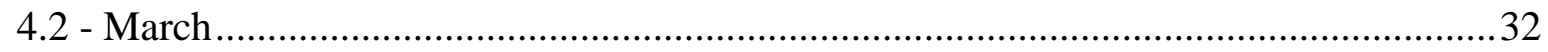

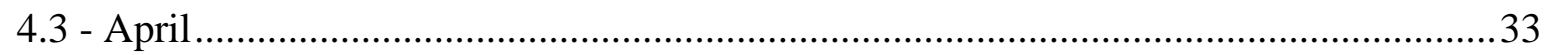

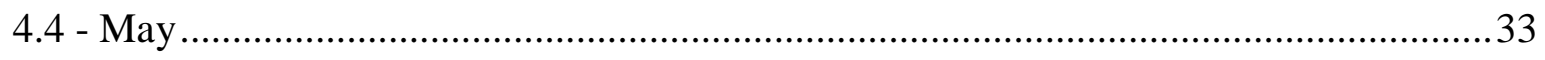

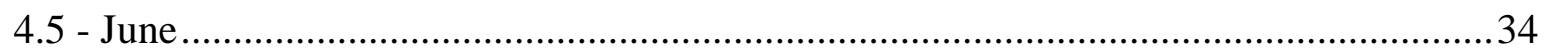

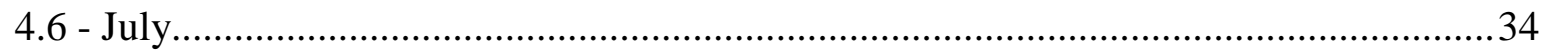

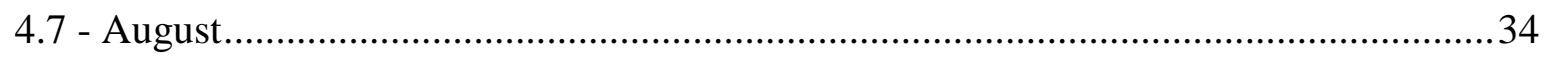

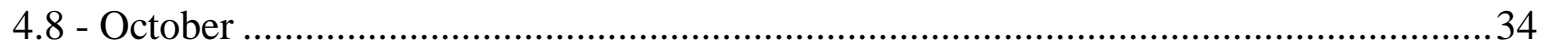

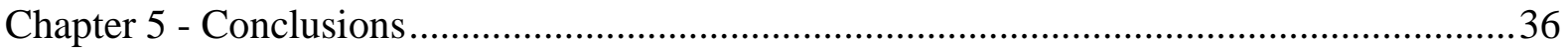

5.1 - Discussion and critique of the development of NacreTech .....................................36

5.2 - Implications of research for theory/practice in your discipline and advanced technology

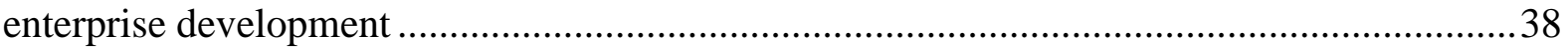

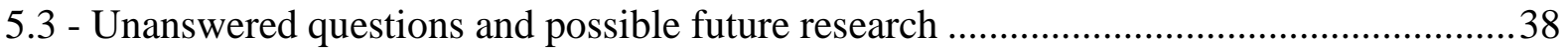

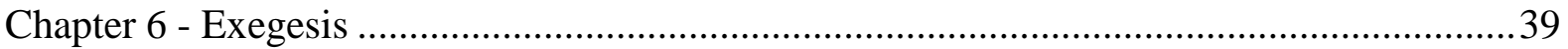

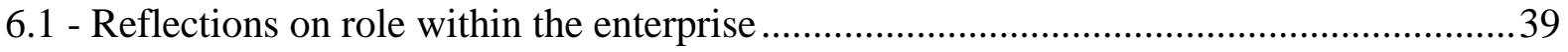

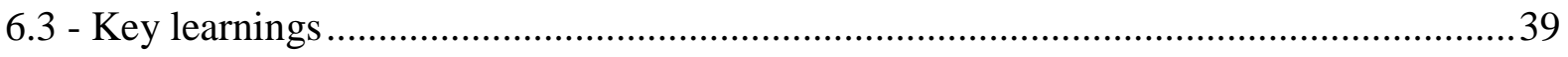

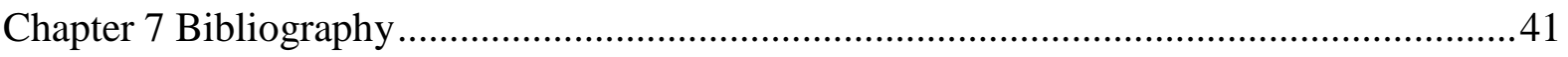




\section{Chapter 1 - Introduction and course overview}

\section{0 - Introduction}

Within this chapter I will be covering the background and supplementary information needed to support this thesis. This chapter will also provide an overview about the Masters of Advanced Technology Enterprise program, the project team and an in-depth description of myself the author, the NacreTech project, and my role within the NacreTech team.

\section{1 - Masters of Advanced Technology Enterprise}

Originating from the physical sciences department at Victoria University of Wellington is the Masters of Advanced Technology Enterprise (MATE) program. This master's program is a one year practice based degree. The goal of the MATE programme is to explore the relationship between scientific research and commercial product development. This exploration is conducted by interdisciplinary teams which are formed around research projects with real commercial potential. Students within the teams explore the relationship between research and commercial objectives by advancing an advanced technology enterprise.

Cumulating at the end of the MATE program each student undertakes an individual supervised piece of research about their experience and role within the program.

\subsection{Project Origin and Project Champion}

\section{Project champion and research Team}

Lead by Kate McGrath, the research team provided an in-depth understanding of the research and advice throughout the MATE course. Over the year the research team worked towards progressing the material to meet the suggested target product profile.

\section{Base research and origins of NacreTech project}

The purpose of the base research was to mimic the process with which molluscs, oysters, and mussels produce a material within their shells called nacre. Nacre is a naturally formed composite of calcium carbonate, in the form of aragonite, and structural proteins such as chitin, 
lustring, and silk-like protein fibres; an example of the resulting material is the semi iridescent inside lining of a mollusc shell.

Synthetic nacre, the method of producing a material similar to naturally formed nacre, was the initial research presented to the team. At a basic level, synthetic nacre, is a composite of a chitin/chitosan natural polymer scaffold and calcium carbonate in the form of aragonite crystals; the primary difference from the natural form is the absence of proteins and contaminants creating a material that is potentially suitable for medical applications.

The material was developed using a combination of known chemical processes. This resulted in the surprising and novel formation of the aragonite integrated into the polymer scaffold. Additionally a process to $3 \mathrm{D}$ print the chitin scaffold followed by the mineralisation has been shown to work in the laboratory. There are limitations are on the maximum wall thickness of the material which is restricted by the limits of diffusion. During experimentation samples have been made in microspheres, films, and printed rings, all $<1 \mathrm{~mm}$ at their maximum thickness.

\section{3 - Project Team}

\section{Michael Mettrick}

Joined the team with an undergraduate commerce degree specialising in business strategy and entrepreneurship, as well as an honours year in Management studies and a prior career in the automotive industry.

\section{Christina Houlihan}

Joined the team with an undergraduate degree in science majoring in Molecular Biology from Otago University. Christina has spent the year employed at IPONZ as a patent investigator.

\section{Thomas Sobeki}

Joined the team with an undergraduate degree from Massey University having majored in Mechatronics. Thomas gained some industry experience in Australia post-graduation before joining the MATE course in Wellington. 


\subsection{Author}

The central question that I have spent my life working on is 'What makes things work?' After finishing high school a decade was spent in the automotive industry learning how vehicles function and how they are maintained. Returning to education, tertiary study became the opportunity to think bigger about larger, more complex, dynamic systems and operations.

A Bachelor of Commerce, majoring in business strategy and entrepreneurship provided the perfect avenue to study both large and small, commercial and private management environments. During my second year of study I was given the opportunity to co-author a piece of original research commissioned by Professor Leo Danna, at the University of Canterbury. The research focused on how organisations 'compete and co-operate' with each other in an isolated environment. Through the success of this research I was chosen to present our findings at the International Conference on Trends and Innovation in Wine Management in Dijon, France. Moving to Wellington, I completed my Honours year at Victoria University in Management. This allowed me to further study complex and dynamic management processes involving entrepreneurial and strategic thinking.

Following on from studying businesses and business strategy, the MATE program brought an opportunity to work within a nascent entrepreneurial organisation. The idea was to gain a level of practical experience to compliment my newfound academic background. The plan was to build a successful start-up with other academically inclined individuals, based within a supportive university environment.

\subsection{NacreTech}

Initially coined during the previous MATE course in the early stages of 2013. NacreTech was named to represent the both the origins of the material and the advanced technology nature of the enterprise. 


\subsection{Role within the NacreTech team}

My role within NacreTech was to develop an understanding of present market aspects, customer needs and aspirations, along with identifying how the current market competitors are meeting the expectations of their customers. Once the existence of unmet market expectations had been established, the role focus switched to the strategic level identifying and developing an optimal business model.

\subsection{Project development timeline, January 2014 - January 2015}

The development timeline of the significant events that occurred throughout the NacreTech project.

\footnotetext{
January $\quad 6$ week intensive course

- Meeting with Anne Barnett of VicLink

- Choose project

- Developed business model canvas

- Formed team

February - Defined decision making process

March - Brainstormed potential material applications including: artificial reef, filtration for mining, environmental shotgun pellets, insulator, bonecarving, medical applications, tiles

- Investigation into medical market looking at orthopaedic bone substitutes

- Identified 'strength' as a potential advantage (narrowing to load bearing orthopaedic bone substitutes)

- Research indicated that there is market saturation of void fillers with approximately more than 12,000 on the market
} 
- Cost per gram for raw materials instigated decision to focus solely on medical applications

- Met with Anne Barnett- NacreTech supplied Memorandum Of Understanding (MOU)

- Research team believed mechanical testing would be done by mid-year

- Research team informed the project team about the limitations on manufacturing size leading to the decision to focus on bone screws

- Identified that the screw shape would be technically difficult to manufacture and would provide a good test case for the manufacturing process

May

- Laboratory observations initiated regarding learning the process to synthesise the material

- Initial freedom to operate search conducted

- Primary market research started- Interviews indicated a need for active and strong biodegradable bone screws. This need is not perceived as been meet by current products, degradation rate and half-life were questioned informing aspects of the TPP investigation

June

- 3D printer failure delaying compression testing

- Interview with regulatory professionals regarding CE mark and FDA regulatory systems. In particular, FDA specialist suggested a drug master file or that a 510k may be possible

- Further secondary research is started

- National phase entry of patent 
- Meeting with Professor Kathryn McGrath regarding further material development. Intention of the research team to focus on $3 \mathrm{D}$ printing of hydrogels

- Found further research confirming that the current screws are not up to requirements and also find out about screws becoming loose in a competitors screw- used primarily for ACL reconstructions

- Determined that 510k application for FDA approval was not possible due to the material being new to medical applications

- Further manufacturing limitations determined such as the maximum material thickness is less than first understood

- Testing degradation in buffer solution confirmed chitin scaffold did not degrade. Surface reaction occurred transforming the calcium carbonate into calcium phosphate.

- Started developing business case and business model

August

- First major market research report gained- medical device market is growing fast especially the relevant sections of the market

- Determined that the bioactive bone screw would be a class III device requiring clinical trials

- Identified 'Bioretec' as potential model company to mimic and gained their investment prospectus

September

- Obtained copy of second major market research report: Biomaterials a global market overview. Confirmed target markets are growing.

- Morgo conference. Group discussion regarding business model and product strategy 
October

- Top up freedom to operate search identified the Stryker patent

- Confirmation that regulatory aspect will in fact inform some of the organisational strategy, not just cause minor hurdles

- Reconfirmed that further applications for the material are intended in the long run i.e. not just bone screws. This will boost the potential returns as ground regulatory work will have been completed

- Australia Biotech Conference attended by Michael. Provided information around production, business model, market penetration may be the issue not technology, crowd funding investment model. Informal meeting with Anne Barnett

November

- Preparation for final presentation

- Met with Anne Barnett to discuss our findings

December

- Final presentation

January

- Third patent landscape search is performed and nothing significant identified 


\section{5 - Methodology}

Based upon the aforementioned timeline, this research looks into the development of a project within the MATE program. The research question that this thesis seeks to answer is:

A mixed methodology approach to exploring the creation of organisation strategy from the perspectives of both the classical strategy frameworks and Sarasvathy's theory of effectuation.

The methodology that has been selected for this piece of research is qualitative; social constructionism through the process of ethnography and critical reflection, followed by a post positivist reflection comparing the latent literature with the previously described experiences. In 'the essential guide to doing your research project' by O'leary (2010), Social constructionism is described as "Theories of knowledge that emphasize that the world is constructed by human beings as they interact and engage in interpretation." Ethnography is described within O'Leary's (2010) text as the study of cultural groups- through the exploration of a way of life from the point of view of its participants.

The intention of the ethnography phase is to create 'thick descriptions' (Greertz, 1973), of the experience of working within a team commercialising some research from within the university. Thick descriptions are described as:

"A thick description ... does more than record what a person is doing. It goes beyond mere fact and surface appearances. It presents detail, context, emotion, and the webs of social relationships that join persons to one another. Thick description evokes emotionality and selffeelings. It inserts history into experience. It establishes the significance of an experience, or the sequence of events, for the person or persons in question. In thick description, the voices, feelings, actions, and meanings of interacting individuals are heard. (Denzin, 1989, p.83)".

Critical reflection based on Bortons' reflective framework as suggested by Jasper (2003) have been used to bring reflection, honesty and depth to the descriptions. The process suggested by Bortons' reflective framework, is an explicit three step process of 'What?', 'So what?' and 'Now what?'. The initial 'What?' phase is used to explain what happened in the scenario and takes an objective perspective. The second 'So what?' phase describes the impact, effects and feelings from and about the event. The third 'Now what?' phase steps one further metaphorical 
step back and asks about the repercussions and about what was learnt, so that given a similar scenario in the future what would be done differently the second time around.

Based on the reflections from the ethnography and reflection phase a post-positivist analysis is intended to compare the 'thick' critical reflection with that which is suggested within the literature. This approach of using qualitative research to test theory has been suggested by Silverman (1993). The primary processes for collecting credible data is through what is known as 'Prolonged engagement' and 'persistent observation' (O'leary, 2010). Prolonged engagement is where there is sufficient investment of time to learn the context and culture. 'Persistent observation' is where due to increased length of time, observations go beyond just the initial observations and instead take time to build deep meaningful observations.

It is through a year of working on and within the MATE programme as the business development and marketing specialist on this commercialisation project, that a saturation of understanding has been developed. This saturation has brought with it an intimate knowledge about the experience of working on and within the NacreTech team. The process of ethnography was selected as the most suitable process for describing the experience of working within an organisation over an extended period of time as suggested by Bryman and Bell (2007). To bring significant depth to the ethnographic descriptions a reflective framework was selected that was simple and easy to follow, as well as bringing out the emotional aspects that expressed themselves throughout the year. Finally a post-positivist reflection was chosen to compare the expressed findings with those which are described in the literature. The reasoning for choosing a post-positivist perspective was twofold. Firstly as the description entailed within the ethnographic phase are highly personalised descriptions they may not perfectly match the findings in a large scale research project with many respondents. And secondly post positivism aligns with my personal perspective of research being able to describe what is and not necessarily what will always be.

The internal personal and interpretive nature of this qualitative research has implications for the reproducibility of results and it recognised, this may not be possible, even with the full process the research followed being explicitly detailed (Bryman \& Bell 2003). Because the full process has being described, the research could be recreated. The contribution to research of this thesis is more related to developing a deeper understanding of relevant literature and thus 
creating a basis for further research and development within the specified area of organisational strategy creation and decision making. 


\section{Chapter 2 - Literature Review}

\section{0 - Introduction}

This literature review seeks to cover the relevant academic knowledge from which to base this thesis. Thus enabling analysis of the experience of working in the NacreTech team during the MATE program. The plan for this literature review is to start by covering the relevant research on business strategy in general, then explore research on entrepreneurship and intrapreneurship as they are both relevant to the context.

To add depth and another complimentary perspective, effectuation and causation will also be covered and used to assist in describing the strategy creation processes as it was developed during the MATE program.

\section{1 - Strategic management}

Over the decades, business strategy has been keenly researched by numerous academics. As far back as Adam Smith in the Sixteenth Century when the 'Wealth of Nations' was originally written, there has been discussion about what it takes for a business venture to be successful (Smith, 2005). One of the components that is described as being important for success, is the competitive strategy (Porter, 1985). Taking the definition of business strategy from 'Contemporary strategic management' by Grant, Butler, Hung and Orr textbook (2011)

"Strategic management is the process of thinking strategically, setting objectives for the organisation and implementing the necessary changes, and measuring the outcomes", (p.4).

There is a depth and diversity of perspectives on strategic management. The 'Strategy Safari' (Mintzberg \& Lampel, 1999) is one such cornerstone text. Mintzberg and Lampel have organised the research on strategic management into 10 categories or 'schools of thought'. The 'schools of thought' covered by the 'Strategy Safari' are used in this review as a framework. The original categorisations are still relevant with only minor additions necessary to incorporate more recently published approaches. This approach of describing most of the notable approaches to strategic management has been selected because NacreTech as an 
organisation went through a number of significant alterations of selected strategy and direction throughout its 2014-2015 year.

Starting with three classical perspectives on organisation strategy. These three perspectives are identified by their normative or standardised approaches. What is most notable about this grouping of perspectives is that they are each in their own way, reflective, cautious and reactive in nature. 'The planning school' in particular suits both developing and examining new ideas as well as planning on a large but intricate scale.

The 'Design school' is thought pay homage to Andrews (1991) and his perspective of strategic management and policy. Design school sees that organisational strategy is made to match internal organisational strengths and weaknesses with external threats and opportunities (SWOT). The simplicity of the 'design school' is that each employee can act as an agent of the firm to achieve the organisations objectives.

In the 'Planning school', formalised, analytically based, systematic strategic planning is the keystone. Ansoff (1957) and Argenti (1968) are classic examples with Hunger and Wheelen (2005) being more modern, each has contributed towards this view. The 'planning school' is significantly similar in reasoning approach to the design school, but uses an in-depth formalised top down prescriptive approach. As illustrated by Myer (1998) this methodology grew to almost uniform uptake, however has since receded. This recession was most notable in unpredictable dynamic markets where adaptability was found to be necessary (Marx, 1991).

The 'Positioning school' is largely analytical in origin, being based upon reacting to standardised situations such those proposed by Porter (1980). This train of thought on analysing to find the optimal position has its origins in military warfare (Schendel, 1985). Inkpen and Choudhury (1995) describe competitive organisational strategy as a tactic or a plan and add that not all successful organisations formally express their strategies, with the implication that this expression can still allow flexibility as needed.

When 'how' the planning process operates in in focus, the six 'schools' are used as analogies:

The 'Entrepreneurial school' follows the intuition and logic of a visionary leader whom follows their entrepreneurial beliefs by working towards achieving huge goals and visions. These goals 
are often communicated in such a way as to mobilise the organisation towards the one objective. One example is the 'narrative approach' (Barry \& Elmes, 1997). The freedom to interpret the narrative leaves the agent free to work towards the prescribed goals with methods that seem best to them.

The 'Cognitive school' survives through mapping and imitation of human cognitive processes. Subjective aspects describe all strategy formations as mental process while the objective side describes strategy formation is an individual process rather than a collective one (Hambrick \& Fredrickson, 2005),(Bowman \& Hurry, 1993).

The emergently focused 'Learning school' describes a constant evolution and refinement process. This learning process includes learning from mistakes and also being ready and able to adapt so that emerging opportunities can be realised. There have been many example of this perspective (Quinn \& College, 1978), (Grant, 2003), and (Gladwell, 2005). Also applicable to this school are the organisations whom plan, 'not to plan' so they can react in the shortest time possible.

The 'Power school' of thought contains both macro and micro perspectives. Macro level power systems aspire towards power over other organisations and includes the collective network of power that the firm can muster within itself and also allied organisations (Chell \& Baines, 2000; Stuart \& Sorenson, 2008). Micro level analysis focuses upon the internal actors and decision making processes within the organisation (Wright, P., Ferris, S. P., Sarin , A., \& Awasthi, 1996).

Outwardly focused, the 'Environmental School' brings with it constructs such as 'sustainable development', 'sustainability', 'contingency theory' and 'population ecology'. From within this perspective, how and where to operate is assessed, also it is beneficial for all stakeholders to align the organisation towards corporate social responsibility, sustainability and other environmental aspects are also realised. Notable examples from this perspective include Burgelman, (1991), Hart (1995) and Laurence \& Webber (2011). This 'Environmental school' also resonates with the traditional and sustainability orientated Maori business principles as displayed by Spiller, Erakovic, Henare and Pio (2010). 
The 'Configuration school' brings up the rear by 'borrowing' stages from other schools of strategic thought. An article by Noda \& Bower (1996) describes this adaptability process where the process changes to suit the needs of the business. By taking components of the other schools the 'Configuration school' endeavours to adapt to the needs of the business by having the right approach available at the right time. The concept goes that the entrepreneurial school is used initially to get the business started, when the usefulness runs out, the learning school is brought in to adapt the business to the market needs and eventually the planning school is brought in to support the company when it has grown to a considerable size and wants to sustain its market share. This dynamic adaptive approach contrasts with the earlier approaches where one approach or process is used at all times of the business lifecycle.

One of the more recent approaches to strategic management is that of 'Strategy dynamics'. Strategy dynamics is an approach that aims to describe both the internal and external natures of creating strategic plans as well as the integrative and adaptive nature of strategic learning and planning (Moncrieff, 1999). Strategy dynamics sees the strategic intent (also known as planned strategy) as a combination of the vision of senior management/ stakeholders, their analysis of both current resources and capabilities and the current operating environment. The analysis, the vision and the resultant plan are all affected by the assumptions and beliefs of the person doing the analysis. It is the implementation of the plan that leads to both new emergent strategies and strategic learning. This strategic learning in turn influences the future strategic intent as well as emerging opportunities. In essence strategy dynamics seeks to create a plan based on resources, capabilities and objectives. Implements the plan and then learn from how it worked as well as integrate new information for the next iteration of the strategic plan.

This lesser known approach of strategy dynamics seeks to combine the key elements and processes that go into competitive strategy formation into on prescriptive and descriptive tool. Strategy dynamics was found to be a useful model for describing organisational change and change capabilities (McGuinness, T., \& Morgan, 2005), also as a tool for evaluating managerial decision making and performance (Gray, M. S., Kunc, M., Morecroft, J. W., \& Rockart, 2008). The key critique of strategy dynamics is regarding the complexity that is inherent within the model. Strategy dynamics was included because it is one of the better strategic management constructs to explain and describe the dynamic systems and decision making processes as well as underlying planned processes that occur in complex business environments. 


\section{3 - Entrepreneurship and Intrapreneurship}

The majority of the previously covered strategic modalities are designed to describe or prescribe the actions that organisations and businesses take. Primarily, the organisations being studied by the research on competitive strategy formation are directed towards fully formed, already operating businesses. The experience of doing the MATE program is about commercialising a piece of research and the entrepreneurial process, not just managing an already established business. As such, the next topic being covered by this literature review is regarding the 'phenomena of entrepreneurship'. Taking the definition of business strategy from Schaper, Volery, Weber, and Lewis (2011),

Entrepreneurship is defined as "The process, brought about by individuals, of identifying new opportunities and converting them into marketable products and services" (p.5).

Business strategy interrelates with commercialisation and entrepreneurship in the area of strategic thinking and also 'the entrepreneurial mindset' (McGrath \& MacMillan, 2000). McGrath and MacMillan described how new opportunities are persued with a passion which aligns with entrepreneuiral research but how the best and most viable ideas are carefully developed into opportunites, this primarily alighns with strategic management research. Alsaaty (2011) take this further by arguing that the only difference between entrepreneurial thinking and strategic thinking is the context. Entrepreneurship is said to be both the creation process towards and also the specific event or phenomena that occurs when a new organisation is created (Bygrave and Hofter 1991).

Entrepreneurship has developed relatively recently into a specific area of business research. However, a standard model of entrepreneurship has been created, and is described by Fisher (2012, p2) “ as a rationally planned, risk-taking and linear process of opportunity recognition and exploitation (e.g., Bhave, 1994; Bird, 1988; Jenkins \& Johnson, 1997; Shane \& Venkataraman, 2000)."

One relatively common approach of entrepreneurial research is to bring theories from other areas of academia and explore how they integrate with and can be used to help describe the phenomena of entrepreneurship. One such article is the Entrepreneurship Safari: A 'Phenomenon-driven search for meaning' (Hector \& Birkinshaw, 2007). Hector and 
Birkinshaw's article is designed to mimic the design and success of Mintzberg and Lampels seminal strategic management text 'The strategy safari' (1999). Hector and Birkinshaw argued that like strategic management being seperated into ten 'schools' of research, entrepreneurship research should be separated into seven thematic areas. Furthermore Hector and Birkenshaw propose that it is the relationship and interaction between 'individuals as entrepreneurs' and the institutional environment that they are operating within that should be a key focus for future entrepreneurship research (Chan \& Makino, 2007 and Tolbert \& Zucker, 1996).

One particularly relevant area of entrepreneurship research is looking into what has been coined 'Intrapreneurship'. Intrapreneurship is when an established business looks to expand into new markets or capitalise upon new opportunities. Entrepreneurship/ Intrapreneurship by Hisrich and Antoncic (1990) is one such article looking into the 'psychological characteristics' and differences between the two constructs of entrepreneurship and intrapreneurship. Hisrich and Antoncic 2001 revisited the topic with a validation study looking to validate and refine intrapreneurship as an international construct through looking at the cross-cultural aspects.

Intrapreneurship is as defined as "Intrapreneurship represent the initiation and implementation of innovative systems and practices within an organization, by some of its staff under the supervision of a manager who takes the role of an intrapreneur, in order to improve the economical performance of the organization," by (Maier \& Pop Zenovia, 2011, p.1).

Seshadri and Tripathy (2006) developed an understanding of intrapreneurship through defining the differences between a 'worker mindset' and identifying that which is required for intrapreneurship to occur. Seshadri and Tripathy found that the main requirement is a shift in the perception of ownership. Fundamentally it is the taking of ownership that is the cornerstone requirement of intrapreneurship. This perception of taking control relates closely with the 'internal locus of control' which is often used in psychological descriptions of entrepreneurs (Brockhaus, 1982; Schaper et al., 2011). 'Internal locus of control' describes as the extent that someone believes that they can control the events that affect them (Schaper et al., 2011).

Intrapreneurship can also be used to describe the activity of commercialising a piece of research from a university through the university's commercialisation office Fang (2004). The complimentary term 'extrapreneurship' has also being developed by Hulsink and Manuel 
(2006) to describe the event of an independent 'spin-off' company being created by an existing organisation.

\section{4 - Effectuation and causation}

A complimentary perspective has developed primarily within entrepreneurship literature, and also to a limited extent business strategy, that of Sarasvathy's theory of effectuation (Sarasvathy, 2001a). Effectuation and causation are used to describe what is often thought of as two competing reasoning methodologies. 'Effectuation processes' can be thought of as describing when someone tries to capitalise upon their current resource base and makes 'something' from it. Causation on the other hand, is more interested in causing something to happen, be it meeting the specific needs of the market or creating the market environment so that the product on offer is wanted by said market. One apt analogy is that of the two chefs (Sarasvathy, 2001b). Chef one works to create a menu based upon what they have in the larder (effectuation). Chef two on the other hand creates their menu first and then fills their larder to suit (Causation).

According to Perry, Chandler and Markova, (2012) effectuation as an aspect of academic research is still in its early stages. Perry et al., (2012) found that the majority of empirical effectuation research does not allow a combination of causation and e effectuation as a possible line of reasoning, due to the perception of entrepreneurs using only one or the other during their strategic thinking processes. Chandler, DeTienne, McKelvie and Mumford, (2011) studied the area of pre-commitments and alliances, with both of them being relevant for both causation and effectuation processes but otherwise they are separate and distinct within each venture creation event. In contrasting literature Fisher (2012) described how there was too much overlap with the two main constructs of effectuation and causation because the factors described by Sarasvathy, are over simplified. 
As cited within Kraaijenbrink, Ratinho and Groen (2011) effectuation literature has focused upon five dimensions (Dew, Sarasathy, Read, \& Wiltbank, 2009; Sarasvathy, 2009; Wiltbank, Read, Dew, \& Sarasvathy, 2009):

Effectual logic is given first with casual logic second;

- Non predictive vs predictive control.

- Means- driven as opposed to goal-driven action.

- Affordable loss as opposed to expected returns.

- Partnerships as opposed to competitive analysis.

- Leveraging as opposed to avoiding contingencies.

One of the less common uses of Sarasvathy's theory of effectuation (Sarasvathy, 2001a) is as a tool to examine the decision making processes within established organisations. Cook and Yamamoto, (2011) describe the use of effectuation based logic and propose that its use can be beneficial to larger organisations, in particular for strategic planning in uncertain markets.

\section{5 - Conclusion}

As shown with this review of relevant literature there is a vast diversity of research and perspectives in the area of business strategy. These perspectives on organisational strategy are used in both prescriptive and descriptive scenarios. This review also described how there is an overlap of research on entrepreneurship and intrapreneurship, and also discussed how the phenomena have similarities. Finally the perspective of effectuation and causation was covered, this perspective was shown to be useful to describe both the phenomenon of entrepreneurship, as well as the decision making processes of established organisations. 


\section{Chapter 3 Description and critical reflection of project development timeline}

\section{Introduction}

This chapter uses an ethnographic and critical reflection approach to describing the significant events that occurred during the 12 months of the MATE program. For the purpose of consistency and honesty the names of the team members have been changed to reflect their academic speciality. This change was included because, as a team there was a strong focus on the different roles of each team member, the specialist knowledge and nature of their academic studies and backgrounds due to the diverse interdisciplinary nature of the MATE program.

\section{1 - January and February}

\section{Project selection}

At the beginning of the MATE program, a six week intensive was designed as a period for the participants to form into teams and select initial projects for the year. Six people had enrolled into the course and 3 projects were formally presented, with an additional fourth project informally pitched by one of the participants. Of these three projects only one matched with my goals and aspirations:

Project one: This project had a champion whom was also a member of the team. He had already decided that he was going to be making all the decisions as it was based on his previous research.

Project two: had a project champion whom was also going to be a team member but he was unable to describe the concept for his project over the course of six weeks, this is while making significant strategic level decisions. This project champion could not even describe the ownership/ management structure other than the fact that he was the CEO. 
Project three: was based upon the idea of using cameras from a Microsoft XBOX connect to do something with. As this project was without technology patents or previous research to base ourselves upon, or a clear application in mind the concept did not gain traction with enough members to form a group.

Project four: was based upon research from one of the university's research laboratories. The project champion Kate McGrath would support the course and the project but would not be a course participant. The base research as described in some detail in the introduction included the process and patent to produce a novel material.

From the provided potions I selected project four as my primary project and indicated an initial interest in project two which was withdrawn before the end of the six week period.

\section{Team formation}

What? We choose the members for our team based largely upon our academic specialities and how they theoretically melded together and aligned towards the objective of commercialising a piece of science. The Scientist with a scientific background, the Engineer from engineering and myself, the Strategist and market researcher from commerce. As we discussed, the conceptual ability of our group was that we would be able to discover and develop a product to satisfy a customer's unmet need (Strategist), understand our material and adapt it so that it can be used in our application (Scientist), and develop the necessary manufacturing techniques and processes to produce the final product (Engineer). We were told about how the material was based upon nacre and vaguely how it was made. We were also told how the project had been started the year before and they had investigated the application of veterinary dental but found that there was no market need and that the material needed at least toxicity and other testing to be even considered for market applications. We were told that since then the material had passed the toxicity testing and that compression testing was due to begin soon.

So what? My initial thoughts were about how the three of us had an ideal project to suit our backgrounds; and we also had ideal backgrounds to suit the project. I was excited about the opportunity but also concerned about the lack of knowledge about the material properties. Furthermore I had background thoughts concerning the fact that the university owned our 
material and thus we would need to licence the material from them in order to operate independently. I was concerned that if we did not manage to licence the material from the university then we would conceptually be working for a company instead of running an independent entrepreneurial organisation.

Then what? In hindsight I would probably do almost the same thing all over again. I also realise that feeling constrained in terms of projects and team members was not an ideal scenario to begin with.

\section{Selection of project, then agreed upon a decision making process.}

What? On one of the final days of the six week intensive in the late afternoon the three of us briefly met to discuss working together for the year. The topic of the day was decision making, which naturally led to us discussing decision making and how we would make decisions as a group.

The Strategist started by proposing that we discuss how we are going to be making decisions. The Engineer said that he had decided that the Scientist should be the team leader and make the decisions. The Strategist was speechless, totally without words, just standing there for a moment gathering his thoughts with his mouth open, head cocked to the side, totally perplexed. After that moment of bafflement he responded by saying no, I disagree that makes no sense. The Engineers response was to say that he was an engineer and engineers follow instructions and that he had decided that the Scientist was the one he wanted to listen to. The Strategist rebutted with a description of how we each have different backgrounds, experiences, and areas of knowledge and that instead we should work together to come to a group consensus. The Scientist added to this by saying that if we could not agree on something then the person with the specialist knowledge could make the final decision. The three of us had come to an agreement, group decision making but final call would given to the specialist role with the relevant knowledge.

So what? I was surprised by the actions of my new teammate, as he had individually and arbitrarily chosen how we as a team would be making decisions and furthermore who was going to be leading the team. I was relieved to have eventually arrived at a more reasonable position and process. 
Then what? This situation should have made me more aware that the three of us needed to work more closely together. If this didn't occur naturally there would be a need create the situation or scenario to bond, connect with and gel as a team.

\section{2 - March}

\section{Decided on initial material application}

What? One of the first jobs for our team was to choose an initial application for the material. During the six week intensive, the entire cohort spent some time brainstorming the potential uses for the new material. A broad variety of applications were created:

- Seeding of coral reef.

- Filter material for mining.

- Shotgun pellets.

- Insulator.

- Bone-carving material.

- Medical- orthopaedics- bone void filler, glue or cement, later identified bone screw.

- Tiles.

- Orthodontic replacement teeth.

- Jewellery.

During the later stages of the six week intensive we had reduced it down to three main applications. Medical, seeding of a coral reef and filter material. It was during March 2014 we found out the cost of raw base materials was significant. \$1 per gram of raw materials was estimated. As a group we then quickly decided that any application would need to be high in value such as medical, military or a low volume specialist use. Following this logic, only the medical device avenue remained, becoming our main focus from this point onwards. During the last few days of March secondary research indicated that there was market saturation of orthopaedic 'void fillers' with greater than 12,000 products on the market. This development meant that we focused on orthopaedic screws and pins as our primary initial applications.

So what? Initially many of the necessary limitations of the material were unknown, I believe this limited the creation of uses due to reduced creative linkages. It seemed very easy and logical for us to target the medical market. Since we all appeared to follow the same logic there was minimal discussion and very quickly a complete consensus. The large number of potential 
competitors within the void filler market signalled that even if we did end up with a superior product to the incumbents, we would still have to battle to get market penetration. Because of this saturation we looked into other uses for biomaterials in medicine in particular orthopaedics since the material had some similarities to human bone.

Than what? So while a limited number of concepts were presented, knowing basic limitations would have been useful to help influence and guide the thought process. It may be useful to pursue limitations and constraints more aggressively in the future, this reasoning has many parallels with those from design thinking (Buchanan, 1992)

\section{3 - April}

\section{Meeting with Anne Barnett}

What? In early April 2014, the NacreTech team meet with Anne Barnett of Viclink to discuss signing a Memorandum of Understanding (MOU). With the assistance of our mentors and team input a document was drafted and tabled at the meeting. As expected Anne wanted to take some time to review the document and said that we should expect to receive a counter offer and have it signed and completed in a few weeks. We contacted Viclink and followed up with Anne and the document multiple times throughout the year, but a MOU was never signed between Viclink and the NacreTech team.

So what? The effect of the MOU going unsigned was that Viclink retained the material rights and nothing was signed over to NacreTech. We continued working on the project, but the drive for success and freedom of operation was reframed as a lower level of responsibility.

Initially, my expectation was that we would have this signed and agreed quite quickly as I see signing an MOU as a foundation document that is a required precedent for the type of work that we were completing within the MATE program. I felt it meant that because Viclink had not signed the document or any variation of it, we were in essence working for them. My perception was that instead of creating an organisation with ourselves as the senior management team around capitalising on the rights to access a novel material; we were instead working on a project, as contractors and therefore there was a finite end point where the project and our findings would be handed back over to Viclink. During the latter half of the MATE 
program the significance that I attributed to the lack of a signed MOU was that the material owner did not trust us to effectively capitalise upon the presented opportunity, instead they wanted to retain control.

Then what? Our efforts as a group seemed altered from this lack of perceived grounding, direction and independence. Because the MOU went unsigned, legitimacy and justification for being an entrepreneurial entity felt to be missing. As a team but without much discussion we adjusted our goals from that of action based on some planning, to that of recommending and planning for future action by the material owners.

What I learnt from this experience is the importance of creating legitimacy among team members and also the importance with stakeholder commitment and buy-in. I expect that outcomes would have been improved if there was communication and alignment of shared goals within both the direct team and the stakeholders. In future projects the parameters and foundation needs to be created to a higher level of legitimacy, as it is this framing that creates the basis and direction for the project to follow.

\section{4 - May}

\section{Primary market research started}

What? After spending the previous few months learning about the project subject material through secondary researching it was time to approach the end users and interview them. My intention was to see if the findings from the secondary research reflected the beliefs of the end users. Using contacts gained from working at Wellington hospital part-time while studying I contacted a few surgeons and arranged interviews. I was aware of trying to make sure that I didn't embarrass myself. Also of making sure that I got useful information from the interviews and tried to not waste their time, as surgeons are known for being time poor and not suffering idiots.

Two initial interviews were conducted:

\section{The first interview}

The first surgeon interview was with the Service Team Leader of the Consultant Surgeons for Wellington hospital. We met at an internal coffee shop and then we walked to his office so we 
could talk a bit more comfortably. This particular Surgeon was an Orthopaedic spinal specialist with decades of experience. He was on the board for the New Zealand Orthopaedic Association. I was slightly intimidated by interviewing someone who was so knowledgeable as my first interview on this topic. This depth of knowledge meant that I was able to ask a lot of important questions and get a good interview with lots of high quality, useful, detailed, and highly representative answers. He was visibly deflated when I told him that we were looking into the application of bone screws. He said that it was a good idea but that he had not had good experiences with bioactive bone screws. His perception was that the advantage of bioactivity and strength had not being realised yet.

He described the current bioactive materials as having limitations, they were either "Strong but not [bio] active enough, or [bio] active and not strong enough."

The surgeon went on to say that because of this, "Bioactive materials are generally not considered for load bearing applications in adults".

\section{The second interview}

The second surgeon interview also went really well. This surgeon was relatively young and had recently moved from the emergency department as a trauma surgeon into the orthopaedic area. I met him at the central hospital café during his lunch break. We built great rapport and had a good conversation about what we as a group have (a novel material), the ways that it could help improve surgical outcomes for both surgeons and also provide better outcomes for patients, and potentially reduce overall costs both physical and psychological. We also discussed his minimal experience with bioactive screws, pins and tacks. The surgeon was particularly interested in the material qualities and in particular the degradation time frame and the degradation half-life strength. He was only on his lunch break he had to go back to work. The surgeon offered to work with us as a group however first he wanted to meet the rest of the team. He wanted to help us with product development as he could see the potential in the type of material we were investigating. We talked about current screws, materials used and how he used mostly used steel or titanium based screws and finally how he personally believed that there had to be a better way.

Later that day an e-mail was sent to the team with the news of how receptive and supportive the surgeon was, and how he wanted to meet with and work with us on the project. 
The next day we met as a team with our mentors. After the normal introductions the Strategist described the interviews and what had been taken from them. Afterwards a description to the team about the offer of development assistance and how there was the initial requirement of meeting the entire team. Neither the Scientist nor the Engineer was agreeable to the idea of meeting with the surgeon. The Strategist tried to convince them of the value to the project and how much we as a group could learn but they would not agree to go meet with him.

So what? The findings from the surgeon interviews were positive and suggested a market need for active and strong bio-absorbable bone screws. This market need is not perceived as been met by current products. Furthermore the degradation rate and the degradation half-life were questioned which after discussion informed some technical requirements for the research team.

With regards to my team members not being receptive to meeting the surgeon I was highly disappointed. My expectation was that they would have wanted to join me in meeting with the surgeon and use his expertise and network of professional contacts to assist the project. I saw this as an untapped opportunity and an incredibly lost opportunity. This resulted in the strategist shifting away from focusing on the specific needs and requirements of the target user and a shift towards the big picture gaps and opportunities at a market level. This shift in focus resulted in a lack of focus on obtaining further user interviews.

Then What? The results from the surgeon interviews did end up contributing a lot to the NacreTech project. I was surprised and encouraged by the positive reception for the proposed target market application of bioabsorbable bone screws.

I was encouraged by the offer of assistance but discouraged by how my team reacted to the offer. If something like this occurred again within a teamwork scenario I would like to think that I would step up and instigate the explicit discussion of individual goals and objectives. 


\section{5 - June}

\section{D printer failure}

What? We had previously being told that mechanical testing was being completed by a contract research company and they would be finished by June 2014. In early June 2014, we were informed they would not be completing testing as the fluid pump within the 3D printer was broken. Also they hadn't been able to make the required shape with the current manufacturing process so they were unable to do the testing anyway. Without knowledge of the specific properties of the material it was impossible to work out the suitability of any specific surgical application. At this point we, as a team, had to make a decision. There were two options; continue with the project, knowing that we were unlikely to find out more of the material specification this year, or find and begin a new project. After some debate we decided to continue with the NacreTech project.

So what? The possibility of ending the current NacreTech project brought out three distinct opinions and three distinct perspectives from the three team members. The individual viewpoints are listed in order of risk aversion:

- The Engineer expressed that this inability to test the material was not even a significant change to the project, as this project was all about planning, not doing, because of the long term nature of medical devices.

- The Scientist believed that we that we had invested too much time and effort to stop and find a new project. It would take too long to get back up to speed, and there is unlikely be a project that used our skills [sets] as well as this one did.

- The Strategist was focused on the possibility of a new project and the opportunities that finding a new project could bring. Concerns were expressed that without the material testing we would be unable to step past theoretical estimations of market suitability.

This was a decisive point which caused my thinking and processes to shift. Initially a variety of entrepreneurial mindsets and skillsets were used in an attempt to meet the market needs, such as Minimum Viable Product (MVP), lean start-up and design thinking methodologies such as suggested by Buchanan (1992). Instead after this incident I switched towards 
intrapreneurial thinking. My perception of my role switched from a practical exercise of being a start-up market development strategist to a strategic thinking exercise about creating the ideal business case for the material at hand, so that the material owners (VicLink) would be provided with the best information available from which to pursue the business opportunity. My initial role had been to develop a deep understanding of the market needs and to understand how our competitors had been trying to meet them and then to start to put that plan into action. Following the June 2014 discussion the project direction was modified to continue building our knowledge base, business strategy and finding a way to create non standardised results for market penetration but not to put any of these things into action.

I was saddened by this change in direction. The reason I chose the MATE course was the opportunity to experience working within a fledgling business. It was the perception of ownership and creation that I was after. The new direction was a switch to a familiar format of researching and then producing a report and associated recommendation; much like an undergraduate project, just taken to the next level in terms of scale, challenge and selected business. One of the repercussions from this was a switch back into the safety of practiced processes. So while I was saddened by the change of direction it did provide a sense of comfort and security to address the rest of the project.

Than what? The decision to continue with the NaceTech project provided insight our individual perception of risk and time. I learnt that my ideas of risk and value of time were vastly different than that of my team members, which provided further knowledge on how to best work with them going forward.

\section{6 - October}

\section{Top up freedom to operate search identified the Stryker patent}

What? The second patient landscape search identified that one of the companies within our target market specialisation of orthopaedics had applied to patent a potentially competitive technology. This discovery forced a rethink of the product strategy that was most suitable for NacreTech to follow. The decision was to plan for both eventualities; focus on first mover 
advantage if we got to the marketplace first, and also to alternatively take advantage of the potentially massive cost savings that a second mover advantage could allow.

So what? Discovering a potentially competitive technology brought about the realisation that being such a nascent organisation meant we were still highly adaptable and therefore still had strategic options available. Furthermore since we did not know the stage of development of the competitor's material we still did not know the entire nature of their patent strategy.

Then what? The realisation that NacreTech was still in a pre-embryonic stage and therefore could be adapted as needed was very freeing. Trying to work out the best strategic options had previously been a slow process of satisficing to find the 'best' answer. With the new found knowledge of NacreTechs manoeuvrability came a freedom to suggest more than one option using a contingency based reasoning approach.

\section{Australia Biotech Conference}

What? The last event that significantly affected the strategy creation of NacreTech was when the Strategist attended the Australia Biotech conference 2014 (AUSBIO). AUSBIO was located at the Gold Coast Convention Centre in the Gold Coast in Australia. The conference was the annual conference for the Biotech Industry Association of Australia, and as such a great variety of businesses were expected to attend.

As quoted from an e-mail from myself to then program director David Bibby about the goals and reasons for wanting attending the conference.

"My intentions for this conference are largely focused upon investment, 'the business case' and innovation within the biotech industry. I will be learning about key industry wide issues and how competing organisations are addressing them. These same organisations will be assessed in terms of key potential complimentary resources that can match, work with or compete with our own. There may also be opportunity to gain insight into the experiences of others whom have faced similar challenges." 
There were many significant and useful findings coming from attending of the AUSBIO conference. The most pertinent resulted from an informal discussion with a representative from the Therapeutic Goods Association (TGA). The TGA regulate the medical device market for Australia. The TGA representative described how he had recently been the TGA investigator for one of our direct competitors products, their bio-absorbable bone screws had flown through the clinical trial with outstanding results. Having previously investigated other similar products for the TGA he said that the ease of gaining regulatory approval was common as recent products had all been successful in the clinical trials. From TGAs perspective there are no major technical problems with current biomaterial products.

The TGA representative also talked about how these products have only managed small scale market penetration; not because of the technical aspects but instead because of the attitudes of the surgeons that selected the medical devices. The TGA representative described how the actions of the surgeons are justified, and described further that surgeons are specifically trained and instructed in such a way as to instil an air of self-confidence and belief that they are 'all knowing'. This air of 'knowing all' has the advantage that patients are soothed and that trust is boosted in the surgeon. According to 'Seeing what others don't' by (Klein, 2013) a disadvantage to 'knowing all' is that you are not open to insights and innovations. Klein describes how when someone has the perception of 'knowing all' they play it safe and relying on existing processes instead of being open to new ones. The playing it safe mentality would therefore inhibit the market penetration of cutting edge medical devices. Later the radically innovative use of targeted crowdfunding was thought to be one potential approach to boost market penetration.

So what? It was the people that were talked to during the conference that returned value for going, just as much as the content that was discussed in the lectures and presentations. The discussions with the TGA representative built on the newfound understanding of strategic adaptability which was realised with the discovery of the competitive patent application.

The Strategist realised that it could be advantageous for NacreTech in its embryonic state to make use of modern methodologies and business models that established and traditional enterprises excluded. Influencing the market penetration of the potential product by was also thought to be desirable. One identified method of increasing market penetration of a new product was to increase the legitimacy of the product through high levels of user engagement 
(Suchman, 2012). A 'crowd funding' model was realised to be largely unexplored within the orthopaedic market and could engage with users while raising capital. Developing the idea further by targeting the end users (Orthopaedic surgeons) as the target market of the crowdfunding is suggested to bring further benefits (Ahlers, Cumming, Guenther, \& Schweizer, 2012).

Then what? The value of industry conferences was clearly presented and visible from attending AUSBIO. The key learnings from the attendance of AUSBIO is the value of both getting out of the office and having a break from the normal day to day environment and also putting yourself out there to make the most of networking opportunities. 


\section{Chapter 4 Analysis of significant decision points along the timeline}

\section{1 - January and February}

\section{Team and Project selection}

At this stage it was too early to indicate a chosen strategy. As a team we self-selected based upon the reasoning that the combination of engineering, commerce and a science students were the perfect team to suit the project needs. In effect we used causation based reasoning to build an effectuation based team. This could be said to be a dualistic approach that looked to match the best, most appropriate resources on hand with what we perceived the market offering would need.

It is also notable that entrepreneurial thinking was present as well as an agreement to collectively work towards creating the project that later we (Re)named NacreTech, this aligns with the entrepreneurial school of strategy and, or the configurations school when using the strategy from the entrepreneurial school as a foundation. Being a project which is owned by Victoria University the implication was that we would be operating as an entrepreneurial team and that a MOU would be required as an agreement to confirm that we did have the rights to access the technology.

Deciding that final decisions based upon an individual's role can be described as a centralised decision making process that resonates with the 'power school' of strategy. Another perspective is that this was an effort of risk aversion by the Engineer so that they could 'do' but would not be burdened by responsibility. As a team we eventually settled on decentralised, task orientated decision making process that resonates with the 'configuration school' by attempting to have the right skill set being used at the right time. Having the right person at the right time also aligns with effectuation by making the most of the resources available at that point in time.

\section{2 - March}

\section{Material Application selection}

Finding out some material limitations helped the team identify a target market. Until that point we were working without constraints and were predictably directionless. Following this initial 
selection, secondary market research helped focus on the target market when it became apparent from this research that the market for void fillers was saturated.

An emergent strategy could be said to have taken hold, because a mix of every type of reasoning and logic that we knew of was implemented. In particular causation reasoning was used to help settle on the initial 'target' application, effectuation based reasoning was also used to try and make the most of the resources at hand once they had been identified.

\section{3 - April}

\section{Meeting with Anne where a MOU is supplied but MOU is unratified}

The second Meeting with Anne from Viclink became something of a landmark event for NacreTech. Not because of the meeting but because the lack of a signed MOU became an early indications to the team that we were operating in an intrapreneurship scenario more so than as a standalone entrepreneurial enterprise.

The lack of an MOU did not change the strategy of NacreTech as such, but it did reinforce and influence the belief that NacreTech was more Intrapreneurship than Entrepreneurship is its orientation.

\section{4 - May}

\section{Primary market research interviews}

After conducting initial exploratory interviews with two surgeons we had a team meeting where I had confirmed to the team, that yes initial interviews indicated that surgical staff have unmet needs with regards to the requirements of fixation devices.

Both the Engineer and the Scientist declined to meet the surgeon, whom had offered to work with us, and support us while we were developing this project. One interpretation of the difference was that that the Strategist was working from a causation perspective where having a surgeon on, or at least supporting the team would be highly beneficial and needed for long term overall development. It appeared that both the Engineer and the Scientist were working from an effectuation perspective were the bundle of capabilities that the group/organisation has is centre and the addition of a surgeon would not directly benefit their role. Declining the 
offered assistance and input of the surgeon the team suggests that both the Engineer and the Scientist were more interested in following the pre-planned pathway which aligns with the 'Planning school' of business strategy, than the 'learning school' where emerging opportunities are capitalised upon.

The other impact on the organisation of was my interpretation of their decline for 'expert' assistance. I interpreted their lack of interest as a disinclination to have an actual and successful business and instead an indication that they wanted to keep the project as a purely theoretical and thus easily manageable planning exercise.

\section{5 - June}

\section{Mechanical testing results and lack of manufacturability causing a pivot from Entrepreneurship to Intrapreneurship}

At this point we changed from an emergent orientated entrepreneurial strategy as suggested within the learning school and shifted towards a more formalised approach such as suggested within the planning school. This alteration of direction can also be described by effectuation and causation logics as a shift from effectuation to causation. Effectuation can describe how NacreTech was initially directed by the want to capitalising upon our resource base (patentable material) and a shift towards causation where we are creating the components for a standardised type of value proposition such that could be presented to investors.

\section{6 - July}

\section{Further manufacturing limitations determined}

\section{7 - August}

\section{Market research report dissemination}

Market segment area is growing. Our specific target market is growing fast, suggesting that this is a good market for the business to get into.

\section{8 - October}

Discovery of competing patent by potential competitor resulting in potential adaption from first mover advantage to second mover advantage 
Adaption in tactics from creating a fixed plan to creating a plan to adapt as needed. How the need for adaption was managed was by taking the original strategic plan and adding a contingency based overlay. By adding a contingency based approach to strategic planning the benefits of top down strategic planning could be realised, as could capitalisation of the emergent opportunities. This contingency based approach has been recommended by Read and Saravarthy (2005) to keep opportunity recognition and strategic learning active. This approach of both planning and simultaneously planning to react aligns with both causation and effectuation. This dualistic approach entailed, working with the resources on hand and also stretching to meet the market needs and requirements. It is also recognised that the aforementioned adaptable strategy could be described within multiple schools of thought, the 'Learning school' and also the 'Positioning school'.

\section{Attendance of AUSBIOTECH 2014}

Discussion with a representative from the TGA suggested that market penetration is lacking, not the technical or clinical ability of current generation bioabsorbable screws.

The representative described how surgeons are trained to come across as 'all knowing' to aid patient psychology could in turn hinder uptake of innovation. He suggested that we try to find a way to increase 'buy-in' such as getting more surgeons involved in the development process.

\section{Exit plan suggestions}

From a high level strategic perspective the largest impact from the trip to AUSBIO was the realisation that slow market penetration and the slow uptake of new technology are major inhibitors for the current competition, and not the technical and clinical aspects of their products as we had previously expected. This realisation impacted the proposed business model and resulted in the suggestion that if a spin-off business is created then the potential benefits of targeted crowdsourcing could potentially overcome or reduce some of the barriers inhibiting market penetration and while also assisting with obtaining some of the not insignificant amounts of funding and development costs. This adjustment is planning is suggestive of an adaption towards the causation mentality of influencing and creating desirable market conditions. 


\section{Chapter 5 - Conclusions}

\section{1 - Discussion and critique of the development of NacreTech}

As described above the progression and development of NacreTech has been far from linear. Starting at the initial entrepreneurial creation phase a dualistic perspective was taken. In general this approach of using both means driven and ends driven reasoning became central to the organisation and its strategy creation processes.

One perceived reason for using a multi directional reasoning process is because of the industry and target marketplace that NacreTech has focused upon, with medical devices having strict regulatory, legal and development requirements. These strict requirements could be said to 'force the hand' of the strategy creation process as there are specific milestones and objectives that needed to be met and a signifigant amount of planning is required as the requirements cover a long development timeframe. But within, or rather around these goal-driven requirements, a certain level and amount of effectual logic persists so that newly emerging opportunities can be capitalised upon.

A second perceived reason for using a dualistic approach is concerning the team based nature of the management and decision making processes of the organisation. The team of NacreTech was made up of three individuals with very different backgrounds and roles within the team. Organisational behaviour literature describes 'group-think' and high levels of group cohesion and as potentially causing a loss of individuality, a loss of diversity and reduced conflict (Nelson, Quick, Wright, \& Adams, 2012). When looking at the NacreTech team 'group-think' and high levels of group cohesion are two descriptions that do not fit. Instead the NacreTech team would be best described as highly individualistic and specialised.

The importance of commitment was one of the most relevant findings that was uncovered from analysing the experience of completing the MATE program. As described earlier the lack of commitment to the success and instead going through their pre-planned pathway significantly impacted the results of the NacreTech team. Within the analysis multiple situations and experiences are detailed. Starting at the beginning of the course our team was presented with the most suitable project being based on a material and patent which the university (Or its subsidiary) wholly owned, while this was convenient the team did not own anything of the project and upon completion would hand the developments back to the project champion. This 
resulted in the team being without a vested interest in the success of the project. The second instance where 'buy in' into the success of the product could have been enabled was the attempt to come to a formal agreement for access to the material and sign an MOU with Viclink. We can realise that they have also had a very busy year, but the absence of a signed MOU resulted in the MATE program being a largely theoretical exercise for the members of NacreTech. In May when an interviewee offered to work with the NacreTech team to assist in realising the commercial nature of the material, there was an absence of necessity from the rest of the team to do what it took to realise the commercial nature of the product. My belief is that they lacked buy-in into the overall company success and interpreted the offer as more work and commitment that might not directly assist them in making their task easier. This point was reinforced when it became apparent that the material needed additional development to even allow standardised testing to take place, and even more so when the development schedule to meet the requirements for testing was not planned to happen until the next year at the earliest.

The previous paragraph addressed the lack of buy in into the project success. The same points can also be investigated through the lens of risk aversion. Risk aversion (Thaler, Tversky, Kahneman, \& Schwartz, 1997) is described as a heightening sensitivity to losses. Those same situations through this alternative perspective of avoiding potential loss make complete sense. Even the first event, project selection can be seen to have indicated a propensity towards reducing the potential for personal risk or loss.

When looking at the overall strategic management creation process the strategy dynamics model proposed by Moncrieff (1999) has the best fit. This model can be used to show how NacreTech initially tried to follow a process of emergence, then switched entirely to a more formal planned approach before settling back, part way between the two with the dualistic approach of having both a formalised plan to meet specific goals and targets, and also retaining the flexibility to adapt and pivot as needed based upon learnings and developments throughout the year. The alternative 'configuration school' would probably be the best alternative as it also uses multiple 'stages' and refinements to the process. But the prescriptive nature of the 'configuration school' is thought to have problems describing the emergent process that unfolded. The alternative would be to develop a version of the 'configuration school' that is more descriptive in nature allowing the organically evolving and learning side of the strategic management process to be followed clearly. 


\section{2 - Implications of research for theory/practice in your discipline and advanced technology enterprise development}

The use of effectuation and causation as a tool to describe the strategic management process was found to be highly successful. The belief is that instead of just describing or prescribing the actions of the organisation, the somewhat hidden reasoning became more apparent.

\section{3 - Unanswered questions and possible future research}

An avenue for research may be the further development and use of causation and effectuation as organisational decision making analysis tools. Furthermore additional research is suggested to help clarify the identified conflict of duality within the causation and effectuation literature. Also the small size of the NacreTech organisation allowed individuals, their decisions and the repercussions to be evaluated from the perspective of causation and effectuation, further research could take this approach and use it to analyse other organisations and gain further insight. 


\section{Chapter 6 - Exegesis}

\section{1 - Reflections on role within the enterprise}

My experience of working within NacreTech was something of a chaotic experience. Having little to no background knowledge on the chosen subject did cause something of a hindrance at first or at least that was my perception. But after a few months of building knowledge about the topic had me feeling somewhat at ease. I can defiantly relate the experience back to my working career where upon starting a new job I have also felt the need for a period of time to gain a reasonable level of comfort.

Differences of opinion from within the team have also created a learning experience. The most relevant being the area of risk aversion which upon analysis was brought to the forefront multiple times with each team member indicating differences in this area. This is one area that I have previously had to be mindful of peoples varying propensity for risk which is also associated with an acceptance the unknown. I have had to be mindful in the past and also during the course because I have found that I am generally okay with large amounts of uncertainty and even enjoy working out what to do when there is only limited amounts of concrete information. My personal affinity towards the ambiguity inclined post- positivist methodology is one indicator that many individuals will not agree with.

The area of risk aversion was relevant throughout the MATE program. My taking of the role of strategist and market researcher within the NacreTech team caused controversy at times, purely because some of the methodologies and strategies that I elected to use or suggested made use of a relatively high level of uncertainty. For example using semi-structured in depth interviews with partly open ended interview questions did not compute with the concrete, yes or no answers that were wanted from me by my team members. I have found this to be highly representative of the working environment where each individual often has their own value, belief and set of heuristics to rely upon.

\section{3 - Key learnings}

They key learnings from this course relate to a variety of areas. Firstly, a reminder that the measures and beliefs that each person uses are created by the individual. Secondly, I learnt a great amount about risk aversion and the individualistic perception of safety and loss. Thirdly, I received a reminder that often times you may not be able to choose the people that you are 
working with, but, you still have to keep working with them. From following and using a causation and effectuation perspective it was found to be effective in analysing decisions at both an organisational level and an individual one. 


\section{Chapter 7 Bibliography}

Ahlers, G. K. C., Cumming, D. J., Guenther, C., \& Schweizer, D. (2012, February 26). Signaling in Equity Crowdfunding. Retrieved from http://dx.doi.org/10.2139/ssrn.2161587

Andrews, K. R. (1991). The concept of corporate strategy. In H. Mintzberg \& J. B. Quinn (Eds.), The strategy process: concepts, contexts, cases (2nd ed., pp. 45-52). Englewood Cliffs: Prentice Hall.

Ansoff, H. I. (1957). Strategies for diversification. Harvard Business Review, 35(5), $113-$ 124.

Argenti, J. (1968). Corporate planning: a practical guide. Allen \& Unwin. Retrieved from http://books.google.co.nz/books/about/Corporate_planning.html?id=FRMPAQAAMAA J\&pgis $=1$

Barry, D., \& Elmes, M. (1997). Strategy retold: Toward a narritive view of strategic discourse. Academy of Management Review, 22(2), 429-452.

Bowman, E. H., \& Hurry, D. (1993). Strategy through the option lens: An integrated view of Resource investments and the incremental-choice process. Academy of Management Review, 18(4), 482-760.

Brockhaus, R. H. (1982). The Psychology of the Entrepreneur. In Encyclopedia of entrepreneurship (pp. 39-57). Retrieved from http://papers.ssrn.com/abstract=1497760

Bryman, A., \& Bell, E. (2007). Business Research Methods (Second.). Oxford: Oxford university press.

Buchanan, R. (1992). Wicked problems in design thinking. Design Issues, 5-21.

Bugelman, R. A. (1991). Intraorganisational ecology of strategy making and organizational theory and field research. Organisational Science, 237-259.

Chan, C. M., \& Makino, S. (2007). Legitimacy and multi-level institutional environments: implications for foreign subsidiary ownership structure. Journal of International Business Studies, 38(4), 621-638. doi:10.1057/palgrave.jibs.8400283

Chandler, G. N., DeTienne, D. R., McKelvie, A., \& Mumford, T. V. (2011). Causation and effectuation processes: A validation study. Journal of Business Venturing, 26, 375-390. Retrieved from file://C:/Users/JAM-pc/Downloads/00b7d52b09a1715b12000000 (3).pdf

Chell, E., \& Baines, S. (2000). Networking, entrepreneurship and microbusiness behaviour. Entrepreneurship \& Regional Development, 12(3), 195-215. doi:10.1080/089856200413464 
Cook, P., \& Yamamoto, R. (2011). Inside the Mind of the Expert Entrepreneur: the Explorer's View of Strategy. Journal of Management and Strategy, 2(3), 77-85. Retrieved from http://www.sciedu.ca/journal/index.php/jms/article/viewFile/404/354

Denzin, N. K. (1989). Interpretive interactionism. Newbury Park: Sage.

Dew, N., Sarasathy, S., Read, S., \& Wiltbank, R. (2009). Affordable loss: behavioral economic aspects of the plunge decision. Strategic Entrepreneurship Journal, 3(2), 105126. doi:10.1002/sej.66

Fisher, G. (2012). Effectuation, Causation, and Bricolage: A Behavioral Comparison of Emerging Theories in Entrepreneurship Research. Entrepreneurship Theory and Practice, 36(5), 1019-1051. doi:10.1111/j.1540-6520.2012.00537.x

Gladwell, M. (2005). Blink: The power of thinking without thinking. Black Bay: Black Bay Books.

Grant, R. (2003). Strategic planning in a turbulent environment: envidence from the oil majors. Strategic Management Journal, 24, 491-517.

Grant, R., Butler, B., Hung, H., \& Orr, S. (2011). Contemporary Strategic Management: An Australasian Perspective. Milton, Qld: Wiley.

Gray, M. S., Kunc, M., Morecroft, J. W., \& Rockart, S. F. (2008). System dynamics and strategy. System Dynamics Review, 24(4), 407-429.

Greertz, C. (1973). The interpretation of cultures. New York: Basic Books.

Hambrick, D. C., \& Fredrickson, J. W. (2005). Are sure you have a strategy? Academy of Management Executive, 24(4), 407-429.

Hart, S. L. (1995). The natural resource-based view of the firm. Academy of Management Review, 20(4), 986-1014.

Hector, R., \& Birkinshaw, J. (2007). Entrepreneurship Safari : A Phenomenon-Driven Search for Meaning. Foundations and Trends in Entrepreneurship, 3(3), 205-255. doi:10.1561/0300000016

Hunger, D. J., \& Wheelen, T. L. (2005). Stratgic management and business policy (10th ed.). Upper Saddle River, NJ: Pearson Education.

Inkpen, A., \& Choudhury, N. (1995). The seeking of strategy where it is not: toward a theory of strategy absence. Strategic Management Journal, 16, 313-323.

Jasper, M. (2003). Beginning reflective practice. Cheltenham: Nelson thorn.

Klein, G. (2013). Seeing what others don't: The remarkable ways we discover insights.

Kraaijenbrink, J., Ratinho, T., \& Groen, A. (2011). Planning effectual growth: a study of effectuations and causation in nascent firms. In Babson College Research 
Entrepreneurship Conference. Syracuse. Retrieved from http://doc.utwente.nl/77524/1/2011.04.14_planning_effectual_growth.pdf

Laurence, A., \& Webber, J. (2011). Business and Society: Corporate strategy, public policy, ethics (11th ed.). Boston: McGraw-Hill.

Maier, V., \& Pop Zenovia, C. (2011). Entrepreneurship versus Intrapreneurship. Review of International Comparative Management Volume, 12(5), 971-976.

Marx, T. (1991). Removing the obstacles to effective strategic planning. Long Range Planning, 24.

McGrath, R., \& MacMillan, I. (2000). The Entrepreneurial Mindset. Harvard Business Review.

McGuinness, T., \& Morgan, R. E. (2005). The effect of market and learning orientation on strategy dynamics: The contributing effects of organisational change capability. Marketing, 1306-1329.

Mintzberg, H., \& Lampel, J. (1999). Reflecting on the strategy process. Sloan Management Review, 40(3), 21-30. Retrieved from http://www.mmt3000.dk/Upload/K4 Mintzberg reflecting on the strategy process (strategy safari).pdf

Moncrieff, J. (1999). Is strategy making a difference? Long Range Planning, 32(2), 273-276. doi:10.1016/S0024-6301(99)00033-3

Myer, R. (1998). Case 5: Strategic planning at Oldelft. In B. de Wit \& R. Myer (Eds.), Strategy process, Content and context. (2nd ed., pp. 963-975). West publishing.

Nelson, D., Quick, J., Wright, S., \& Adams, C. (2012, March 29). ORGB Asia-Pacific Edition. Retrieved from http://ecite.utas.edu.au/77321

Noda, T., \& Bower, J. (1996). Strategy as a iterated process of resource allocation. Strategic Management Journal, 17, 159-192.

O'leary, Z. (2010). The essential guide to doing your research project. Thousand Oaks: Sage Publications.

Perry, J. T., Chandler, G. N., \& Markova, G. (2012). Entrepreneurial Effectuation: A Review and Suggestions for Future Research. Entrepreneurship Theory and Practice, 36(4), 837-861. doi:10.1111/j.1540-6520.2010.00435.x

Porter, M. E. (1980). Competitive Strategy: Techniques for analyzing industries and competitors. New York: The free press.

Porter, M. E. (1985). Competitive strategy: Creating and sustaining superior performance. New York: The free.

Quinn, J. B., \& College, D. (1978). Strategic change: “logical incrementalism.” Sloan Management Review, Fall, 7-21. 
Read, S., \& Saravathy, S. (2005). Knowing what to do and doing what you know:

Effectuation as a form of entrepreneurial expertise. The Journal of Private Equity, 9(1), $45-62$.

Sarasvathy, S. D. (2001a). Causation and Effectuation: Toward a Theoretical Shift from Economic Inevitability to Entrepreneurial Contingency. Academy of Management Review, 26, 243-263. doi:10.2307/259121

Sarasvathy, S. D. (2001b). What Makes Entrepreneurs Entrepreneurial? University of Washington School of Business. Retrieved from http://papers.ssrn.com/abstract=909038

Sarasvathy, S. D. (2009). Effectuation: Elements of Entrepreneurial Expertise. Edward Elgar Publishing. Retrieved from https://books.google.com/books?hl=en\&lr=\&id=Ve0_8nJcOD0C\&pgis=1

Schaper, M., Volery, T., Weber, P., \& Lewis, K. C. N.-H. P. S. 2011. (2011). Entrepreneurship and small business (3rd Asia-P.). Milton, Qld: John Wiley \& Sons Australia.

Schendel, D. E. (1985). Strategic management and strategic marketing: What is strategic about either one? In H. Thomas \& D. Gardner (Eds.), Strategic management and strategic marketing (pp. 41-63). New York: Wiley and sons.

Silverman, D. (1993). Interpreting qualitative data: methods for analysing qualitative data. London: Sage.

Smith, A. (2005). Wealth of Nations. Chicago: University of Chicago Bookstore.

Stuart, T. E., \& Sorenson, O. (2008). Strategic networks and Entrepreneurial ventures. Strategic Entrepreneurship Journal, 227(2007), 211-227. doi:10.1002/sej

Suchman, M. C. (2012). Managing Legitimacy: Strategic and Institutional Approaches. The Academy of Management Review, 20(3), 571-610.

Thaler, R. H., Tversky, A., Kahneman, D., \& Schwartz, A. (1997). The Effect of Myopia and Loss Aversion on Risk Taking: An Experimental Test. The Quaterly Journal of Economics, 112(2), 647-661. Retrieved from http://www.jstor.org/stable/2951249

Tolbert, P. S., \& Zucker, L. G. (1996). The Institutionalization of Institutional Theory. In S. Clegg, C. Hardy, \& W. Nord (Eds.), Handbook of organization studies (pp. 175-190). London: Sage Publications.

Wiltbank, R., Read, S., Dew, N., \& Sarasvathy, S. D. (2009). Prediction and control under uncertainty: Outcomes in angel investing. Journal of Business Venturing, 24(2), 116133. doi:10.1016/j.jbusvent.2007.11.004

Wright, P., Ferris, S. P., Sarin , A., \& Awasthi, V. (1996). Impact of corporate insider, blockholder and institutional equity ownership on firm risk taking. Academy of Management Review, 39(2), 441-463. 